\title{
Living Life and Doing Things Together: collaborative research with couples where one partner has a diagnosis of dementia
}

DOI:

$10.1177 / 1049732318786944$

\section{Document Version}

Accepted author manuscript

Link to publication record in Manchester Research Explorer

Citation for published version (APA):

Bielsten, T., Keady, J., Hellström, I., Kullberg, A., \& Lasrado, R. (2018). Living Life and Doing Things Together: collaborative research with couples where one partner has a diagnosis of dementia. Qualitative Health Research, 28(11). https://doi.org/10.1177/1049732318786944

\section{Published in:}

Qualitative Health Research

\section{Citing this paper}

Please note that where the full-text provided on Manchester Research Explorer is the Author Accepted Manuscript or Proof version this may differ from the final Published version. If citing, it is advised that you check and use the publisher's definitive version.

\section{General rights}

Copyright and moral rights for the publications made accessible in the Research Explorer are retained by the authors and/or other copyright owners and it is a condition of accessing publications that users recognise and abide by the legal requirements associated with these rights.

\section{Takedown policy}

If you believe that this document breaches copyright please refer to the University of Manchester's Takedown Procedures [http://man.ac.uk/04Y6Bo] or contact uml.scholarlycommunications@manchester.ac.uk providing relevant details, so we can investigate your claim.

\section{OPEN ACCESS}




\section{Qualitative Health Research}

\section{Living Life and Doing Things Together: collaborative research with couples where one partner has a diagnosis of dementia}

\begin{tabular}{|r|l|}
\hline Journal: & Qualitative Health Research \\
\hline Manuscript ID & QHR-2017-0939.R3 \\
\hline Manuscript Type: & Research Article \\
\hline Keywords: & $\begin{array}{l}\text { Dementia, Nursing, Self-Efficacy < Self, Caregivers, Caretaking, } \\
\text { Alzheimer's disease < Neurology, Neurological Disorders }\end{array}$ \\
\hline Regions, Cultures, and \\
Peoples: & Europe, Europeans \\
\hline Methods: & $\begin{array}{l}\text { Implementation < Research, Collaborative < Research Design, Mixed } \\
\text { Methods < Research Design }\end{array}$ \\
\hline
\end{tabular}

\section{SCHOLARONE ${ }^{\text {m }}$}

Manuscripts 


\section{Introduction}

In this article, we report on the progress of the "Living Life and Doing things Together" study, an international project with the overall aim of developing an empirically-based self-management guide for couples living at home and where one partner has a diagnosis of dementia. The "Living Life and Doing Things Together" study is one of eight work programs which form the five year (2014-2019) ESRC/NIHR "Neighbourhoods and Dementia" mixed methods study (Keady, 2014; and see: www.neighbourhoodsanddementia.org). The Neighbourhoods and Dementia study is funded as part of the first UK Prime Minister's Challenge on Dementia (Department of Health, 2012) with a focus on the everyday connection of people with dementia to spaces, places and people. The study "Living Life and Doing Things Together" addresses couples where one partner has a diagnosis of dementia and has the overall objective to develop, and test, a self-management guide which will be delivered via an application called "DemPower" in a feasibility trial conducted in Sweden and the UK during 2018. As a first step of the "Living Life and Doing Things Together" study, the research team undertook a narrative review (Bielsten \& Hellström, 2017a) and a scoping review (Bielsten \& Hellström, 2017b) of the literature with the aim to map interventions for couples where one partner has a diagnosis of dementia. The reviews provided an overall view of types and objectives of couple-based interventions and to what extent they addressed the couple's relationship. Salient findings of the reviews indicated that most dyadic interventions, including joint interventions (both partners participating together), lack a relational focus and a genuine dyadic approach, which is a phenomenon highlighted by several other authors (see for example: Moon \& Adams, 2012; Van't 
Leven et al. 2013; Merrick, Camic \& O'Shaughnessy, 2016); most interventions required participating couples to travel to the location of the intervention and/or that the intervention was dependent on the delivery by professionals, which indicated a lack of easily accessible support; the absence of a salutogenic approach in which the couples' resources and strengths were the main focus. The lack of relationship- and strength based support guided our overall approach to the development of the self-management guide, which is inspired by salutogenisis (Antonovsky, 1979, 1987) and self-management in dementia (Martin, Turner, Wallace \& Bradbury, 2013). As an authorship and research team, our stance has been to view the couple as a 'unit' interdependent on each other's wellbeing and resources. In the present article we will report on the process of identifying relevant content for the self-management guide, and demonstrate how the study design of collaborative research enhanced the trustworthiness of the findings.

\section{Background}

The progressive nature of dementia brings challenges to couples' relationships by demanding constant adaptation to new situations and roles. Relationship quality might deteriorate as a result of the transition from a mutually interdependent relationship toward a caregiver-care-receiver relationship (Ingersoll-Dayton, Spencer, Kwak, Scherrer, \& Campbell, 2013; Hellström, Nolan \& Lundh, 2007). This transition is often at the expense of the sense of "couplehood", a concept described as feelings of belonging to a "We" (Kaplan, 2001, p. 87). Low relationship quality in couples has shown to have a negative impact on wellbeing in several dimensions, for example it: accelerates cognitive and functional decline (Norton, Piercy, Rabins, Green, Breitner \& Ostbye et al. 2009); predicts the need of moving to a special accommodation (Spruytte, Van Audenhove \& 
Lammertyn, 2001; Brodaty, Gresham \& Luscome, 1997); increases the risk of depression in both the person with dementia and the partner; increases strain; and decrease selfefficacy in partners (Ablitt, Jones \& Muers, 2009). Despite all the evidence of relationship quality as a crucial factor for wellbeing, and for the prevention of negative consequences, support aimed at couples' relationships is scarce. Accessible support for couples, including dyadic support, are often based on the individual which leads to barriers in acknowledging needs for relationship based support (Bielsten \& Hellström, 2017a,b).

In recent years, several authors have highlighted the urgent need for interventions that support couples' relationships and interaction (see for example Ablitt et al. 2009; Bielsten \& Hellström, 2017a,b; McGovern, 2011; Balfour, 2014). Support aimed at couples where one partner has a diagnosis of dementia would be advised to target the couples' interaction, communication and closeness in the context of everyday life, as communication and interaction often become problematic areas for couples living with dementia and has a significant impact on relationship quality (Reilly, Relkin \& Zbrozek, 2006; Boots, de Vugt, Withagen, Kempen \& Verhey, 2016; Werthon \& Monk, 2008). Whilst most couples will face difficulties and losses in these areas, the impact of negative experiences can be reduced with maintained mutuality and positive interaction within the relationship (Balfour, 2014). Developing this point further, Balfour (2014) highlights the importance of everyday life and to help the couple to "find new meaning and new ways of thinking precisely grounded in the couple's daily living” (p. 314). Balfour's "therapeutic couple work" thus demands a professional guiding the sessions, resulting in 
limitations for everyday use and for the couple to engage in continuously and when it suits them best.

Couple's relationship in dementia is often assumed to be burdensome, which reflects the predominant problem-based and symptom-oriented support accessible for couples with dementia. The targets of the support are most commonly focused on the caregiver-care-receiver roles, cognitive function of the person with dementia, and the partners strain and burden (Bielsten \& Hellström, 2017a, b; Purkis \& Ceci, 2015; Martire, Schulz, Helgeson \& Saghafi, 2010). This position is the complete opposite to the approach within most other chronic diseases where the goal is to learn how to live as well as possible with the disease (Robinson, 2017), learn self-management skills, promote coping strategies and gain self-efficacy (Martin, Turner, Wallace, Stanley, Jesuthasan \& Bradbury, 2015; Barlow, Wright, Sheasby, Turner, \& Hainsworth, 2002).

The term salutogenisis originates from Antonovsky's $(1979,1987)$ healthoriented paradigm with the core concept of Sense of Coherence. Sense of Coherence involves the three components, namely comprehensibility, manageability, and meaningfulness, which are seen as crucial factors for successful coping. Comprehensibility implies the experience of perceived predictability, order and "cognitive sense" of stimuli. Manageability implies the extent to which the individual perceive that $\mathrm{s} / \mathrm{he}$ has the resources (personal and social) to face and cope with demands. Meaningfulness, the most important factor according to Antonovsky, refers to sense of meaning, purpose and motivation to deal with demands (Antonovsky, 1979, 1987. Lillekroken, Slettebo \& Hauge, 2015). The concept of Sense of Coherence is originally applied to the individual, but one could argue for it to be applicable to couple's 
relationship when/if the couple is seen as a unit that needs to perceive dyadic comprehensibility, manageability, and meaningfulness. Perceived meaningfulness of the loving relationship and everyday life may be the most important factors that motivate couples, where one partner has a diagnosis of dementia, to face the on-going challenges to their relationship (Keady \& Nolan, 2003; McGovern, 2011). This, in turn, highlights the need for new types of support with a dyadic approach and with the aim to support couples' efforts in sustaining everyday relationship quality and wellbeing.

\title{
The study
}

\begin{abstract}
Aim
The aim of this study is to identify relevant content for a self-management guide by using the outcomes of previous research in combination with knowledge and experiences from couples where one partner has a diagnosis of dementia.
\end{abstract}

\section{Methodology}

Drawing on the work of Fereday and Muir (2006), we used Alfred Schutz's (1973)

framework of first- and second order constructs as an overall methodology for the study, and their hybrid approach of thematic analysis for analysis of the data.

\begin{abstract}
Alfred Schutz's (1973) framework of first- and second order constructs was used as an overall methodology. Schutz refer to the subjective meaning as the first-order constructs, meaning that first-order constructs are information and knowledge from people with lived experience. The second-order constructs are the scientific interpretation and reproduction which trustworthiness is dependent on whether the first-order constructs has been
\end{abstract}


safeguarded or not. In addition to the demand for subjective meaning, second order constructs also need to be connected to existing scientific theory and common sense. Schutz (1973) has formulated three postulates for scientific constructs, which guided our process:

Logical consistency: The system of typical constructs designed by the researcher has to be clear and distinct and fully compatible with formal logic, which is linked to universal meaning, objectivity and rationality.

Subjective interpretation: The model must grasp the subjective meaning of the actor.

Adequacy: The constructs of the researcher must have consistency with commonsense experience and be recognizable and understandable for actors in everyday life (Schutz, 1973; Fereday \& Muir, 2006).

\section{Method}

The study involved three phases:

(1) Phase 1 was a comprehensive literature search of previous research related to couplehood and wellbeing in dementia. The literature search informed a draft framework of themes outlined to be potential targets for the self-management guide.

(2) Phase 2 involved ten interviews, guided by the draft framework, with five couples where one partner has a diagnosis of dementia in Sweden. In this phase the predetermined themes were presented to the couples with the purpose of confirming or rejecting the relevance of the themes. This phase also enabled the 
process of adding subjective meaning to the themes and allowed for couples to add new themes of relevance.

(3) Phase 3 involved authentications of the findings within expert groups of people with dementia and carers in Sweden and in UK. This phase enabled testing of the empirical validity of the themes as sensitizing concepts, and the transferability to a UK context. Meetings with expert groups also enabled the collaborative approach to be maintained throughout the study.

\section{Phase 1. Literature search}

A literature search of previous research related to couplehood and everyday wellbeing in dementia was conducted. Fourteen recurrent themes were identified in the literature and outlined as potential targets for the self-management guide. The identified themes formed a draft framework that guided the data collection in the second phase of the study.

Themes, shortened rationales and supporting literature are displayed in table 1.

\section{Table 1. Identified themes and supporting literature}

\begin{tabular}{|l|l|l|}
\hline Name of themes & Rationale & Supporting Literature \\
\hline $\begin{array}{l}\text { The meaning of } \\
\text { home }\end{array}$ & $\begin{array}{l}\text { Having the opportunity and support to age in } \\
\text { place, in the own home, neighborhood and in a } \\
\text { community. }\end{array}$ & $\begin{array}{l}\text { Wiles et al. 2012; Gillsjö et al. 2011; } \\
\text { Soilemezi et al. 2017; Ward et al. 2017; Keady } \\
\text { et al. 2012; Keady et al. 2014; Nygård, 2004 }\end{array}$ \\
\hline $\begin{array}{l}\text { Comfort/safety } \\
\text { inside home } \\
\text { Comfort/safety } \\
\text { outside home }\end{array}$ & $\begin{array}{l}\text { Being able to stay in familiar environments. } \\
\text { Importance of facilitating daily activities and } \\
\text { chores to promote independence and activity } \\
\text { inside the home and in the neighborhood. }\end{array}$ & $\begin{array}{l}\text { Tanner et al. 2008; Torrington, 2009; Werthon } \\
\text { \& Monk, 2008; Soilemezi et al. 2017; Mitchell } \\
\text { \& Burton, 2010; Keady et al. 2012; Ward et al. } \\
\text { 2017; Keady et al. 2014 }\end{array}$ \\
\hline Physical wellbeing & $\begin{array}{l}\text { Physical activity as a source of doing things } \\
\text { together as a couple and to promote healthy } \\
\text { aging, cognitive function and physical well- } \\
\text { being. }\end{array}$ & $\begin{array}{l}\text { Dal Bello-Haas et al. 2014; Bowes et al. 2013; } \\
\text { Lamotte et al. 2017; Hernández et al. 2015; } \\
\text { Wei-Wei et al. 2016; Duggan et al., 2008; } \\
\text { Pitkälä et al. 2010; World Health Organization, } \\
\text { 2010 }\end{array}$ \\
\hline Mental wellbeing & $\begin{array}{l}\text { Cognitive stimulation with the aim to improve } \\
\text { or sustain ability to communicate and interact } \\
\text { with each other. }\end{array}$ & $\begin{array}{l}\text { Woods et al. 2012; van Nes, 2013; Genoe \& } \\
\text { 2016; Spector et al., 2017 }\end{array}$ \\
\hline $\begin{array}{l}\text { Individual } \\
\text { activities }\end{array}$ & $\begin{array}{l}\text { Individual activities as a source to gain } \\
\text { strength and to nurture social relationships. }\end{array}$ & $\begin{array}{l}\text { van Nes, 2013; Robinson et al. 2005; } \\
\text { Hellström et al. 2007; Bergman et al. 2016; } \\
\text { Solum et al. 2013; }\end{array}$ \\
\hline $\begin{array}{l}\text { Meeting with } \\
\text { peers }\end{array}$ & $\begin{array}{l}\text { Having the opportunity to share experiences } \\
\text { with people in a similar situation. }\end{array}$ & $\begin{array}{l}\text { Söderhamn et al. 2014 Clare et al. 2008; Leung } \\
\text { et al. 2015; Toms et al. 2015; Keyes et al. 2016 }\end{array}$ \\
\hline
\end{tabular}




\begin{tabular}{|l|l|l|}
\hline & & \\
\hline Informing others & $\begin{array}{l}\text { Preventing isolation due to stigma and negative } \\
\text { feelings. Disclosure. }\end{array}$ & $\begin{array}{l}\text { McRae, 2008 \& 2011; Genoe \& Dupuis, 2014; } \\
\text { Hellström \& Torres, 2013; Alzheimer's } \\
\text { Association; Quinn et al. 2008 }\end{array}$ \\
\hline Stress & $\begin{array}{l}\text { Avoiding stressful situations that have negative } \\
\text { impact on cognitive function and sense of self. }\end{array}$ & $\begin{array}{l}\text { Alzheimer's association, 2015; Brodaty \& } \\
\text { Donkin, 2009; Groat and Weems, 2009; } \\
\text { Lindsay et al., 2012 }\end{array}$ \\
\hline $\begin{array}{l}\text { Future and } \\
\text { planning }\end{array}$ & $\begin{array}{l}\text { Planning ahead for future impact of the } \\
\text { condition with the aim of increased sense of } \\
\text { control. }\end{array}$ & $\begin{array}{l}\text { 2015; Alzheimer's Association; Hellström \& } \\
\text { Torres, 2016 }\end{array}$ \\
\hline $\begin{array}{l}\text { Adapting activity } \\
\text { to capability }\end{array}$ & $\begin{array}{l}\text { Adapting capability to activity (and goals of } \\
\text { activities), in order to feel that activities are } \\
\text { manageable and successful. }\end{array}$ & $\begin{array}{l}\text { Genoe \& Dupuis, 2014, McGovern, 2015; } \\
\text { Groat and Weems, 2009; McRae, 2010 }\end{array}$ \\
\hline $\begin{array}{l}\text { Doing things } \\
\text { together }\end{array}$ & $\begin{array}{l}\text { Everyday chores and activities are meaningful } \\
\text { and an important source of pleasure and } \\
\text { opportunity to do things together. }\end{array}$ & $\begin{array}{l}\text { Hellström et al. 2007; Balfour, 2014; Genoe \& } \\
\text { Dupuis, 2014; Reilly et al. 2006. }\end{array}$ \\
\hline $\begin{array}{l}\text { Being active and } \\
\text { supportive }\end{array}$ & $\begin{array}{l}\text { The balance between support and keeping } \\
\text { sense of independence. Supporting personhood } \\
\text { and meaningful activity. }\end{array}$ & $\begin{array}{l}\text { McRae, 2011; Nygård, 2004; Vernooij-Dassen } \\
\text { \& Moniz-Cook, 2016 }\end{array}$ \\
\hline $\begin{array}{l}\text { Communication } \\
\text { and interaction }\end{array}$ & $\begin{array}{l}\text { Being able to spend time together, interact and } \\
\text { have a joy-full time, to maintain value in the } \\
\text { relationship. Learning strategies to manage } \\
\text { communication and interaction. }\end{array}$ & $\begin{array}{l}\text { Reilly et al. 2006; Boots et al. 2016; Werthon } \\
\text { \& Monk, 2008; Bigonnesse et al. 2014; Tanner } \\
\text { et al. 2008; Berry, 2014. McGovern, 2011 }\end{array}$ \\
\hline Avoiding conflicts & $\begin{array}{l}\text { Prevention of conflicts and sustaining positive } \\
\text { communication. }\end{array}$ & $\begin{array}{l}\text { Hellström et al. 2007; McGovern, 2011; } \\
\text { Ingebretsen \& Solem, 1998 }\end{array}$ \\
\hline
\end{tabular}

Key words used for literature search: "couple", "spouses", "dementia", "wellbeing", "quality of life" "relationship" "everyday life" "home" and related concepts. Databases: PubMed, Cinahl, Scopus, Web of Science and PsycInfo.

\section{Phase 2. Interviews with people with dementia and partners}

Participants were a convenience sample of five Swedish couples $(n=10)$ recruited from a

memory clinic. Staff at the memory clinic approached the couples and mediated the

contact between researchers and participants. Inclusion criteria were: couples of any

gender, living in their own home and a diagnosis of dementia for one partner. Participant characteristics are displayed in table 2 .

Table 2. Participant characteristics

\begin{tabular}{|l|l|l|l|l|l|}
\hline & Couple 1 & Couple 2 & Couple 3 & Couple 4 & Couple 5 \\
\hline Gender person with dementia/partner & $\mathrm{F} / \mathrm{M}$ & $\mathrm{M} / \mathrm{F}$ & $\mathrm{M} / \mathrm{F}$ & $\mathrm{F} / \mathrm{M}$ & $\mathrm{M} / \mathrm{F}$ \\
\hline Age person with dementia/Partner & $74 / 77$ & $71 / 67$ & $74 / 72$ & $74 / 74$ & $77 / 73$ \\
\hline Diagnosis of dementia & Alzheimer & Alzheimer & Alzheimer & Alzheimer & Alzheimer \\
\hline
\end{tabular}




\section{Data collection}

Data consisted of ten semi-structured interviews (one initial and one follow-up for each couple), and written comments from the couples. The framework of themes, constructed in phase 1 (table 1), guided the interviews. The primary objectives of the interviews were to confirm the relevance of themes, represent subjective meaning of the themes, and to add new themes of relevance from the interview data. Participants were asked to assess the relevance of the themes and to give examples from their own lives related to the themes. Each theme in the draft framework was presented to couples with a "trigger" in shape of a quote, which was followed by a question (see example in table 3 ). In order to allow new perspectives outside the draft framework, the main interviewer (first author) was responsive to new topics during the interviews. The first author, who is a specialist nurse in the care of older people, and has several years' experience of communication with people with dementia and their family members, conducted all the interviews. The couples decided when and where the interviews would be held. All couples chose to be interviewed in their home and were interviewed together as a unit (Sohier, 1995).

Written informed consent was collected from all participants before the first interview started. Each couple kept the draft framework with the added triggers and questions to reflect upon in between interviews. This created conditions for couples to participate in different types of ways and when it best suited them both. Couples also received material to write comments of the themes in the draft framework, and could also choose to record their reflections/discussions of the themes by using a voice recorder, also with the intention to offer various opportunities to participate (Bartlett, 2012). Three 
couples chose to write comments about the themes between the interviews and two couples discussed all of the themes with the interviewer during interviews and choose not to write any comments between the interviews. No couple chose to use the voice recorder. The second interview was a follow-up interview including collection of written comments and was conducted approximately two weeks after the first interview. The interviews length varied between 40-90 minutes. Interviews were audio recorded and transcribed verbatim and all written comments were gathered in documents.

Table 3. Example from the draft framework, as presented for couples

Theme: Meeting other couples with dementia
*"When we meet in the group, it is nice to know that you are not alone and that there are others like us.
You can relax, share experiences and get great tips from each other"
What are your thoughts of meeting other couples living with dementia?
* Trigger
Data analysis

\section{The hybrid approach of thematic analysis}

Thematic analysis can be used for both deductive and inductive analysis, which means that themes can be brought to the data set, and/or brought from the dataset, in order to interpret data. The analysis followed the hybrid approach of thematic analysis by Fereday and Muir (2006), which combines deductive and inductive processes.

\section{Development of a template of themes}

The first step involved the development of a template of themes. We used the themes of the draft framework (table 1) for this purpose. The template consisted of the names of the themes, definitions of what the themes concerns, and a description of how to know when 
the themes occurred in the interview data. An example of the template is displayed in table 4 .

Table 4. Example from the template of themes

\begin{tabular}{|c|c|}
\hline \multicolumn{2}{|l|}{ Theme 1} \\
\hline Name of theme: & The meaning of home \\
\hline Definition: & Physical and emotional space of home \\
\hline Description: & Description of home or feelings of being at home and in familiar surroundings. \\
\hline \multicolumn{2}{|l|}{ Theme 2} \\
\hline Name of theme: & Comfort/safety inside home \\
\hline Definition: & Physical safety, adaptions facilitating everyday life. \\
\hline Description & Descriptions of comfort, safety and function of home related to everyday living \\
\hline
\end{tabular}

\section{Applying themes from the template to the interview data (deductive} analysis)

The transcribed interviews, and couples' written comments, were read multiple times and text of potential interest highlighted. Testing of themes applicability to the data was undertaken using the first transcribed interview as a test piece. First and last author of this article discussed the applicability of the themes on the basis of the test piece. No modifications of the template were required. Themes from the template were matched with segments of data that was representative of the themes (table 5).

Table 5. Applying a theme from the template

\begin{tabular}{ll}
\hline Theme from the manual: & The meaning of home \\
\hline Segment from transcribed interviews & $\begin{array}{l}\text { "I feel peace and harmony in my home. We } \\
\text { like to go out as well, but there's nothing better } \\
\text { than coming home when you've been out, } \\
\text { closing the door behind us and just relax" }\end{array}$ \\
\hline
\end{tabular}




\section{Additional theming of the interview data (inductive analysis) and connection of themes}

The "theming" process also included the inductive approach where data-driven themes were applied to segments of data that described new themes not included in the template (table 6). Themes associated to each other (from the template and data-driven), were then clustered and connected in order to form main themes.

Table 6. Example of a data-driven theme

\begin{tabular}{ll}
\hline Data-driven theme: & State of mind/living as usual \\
\hline Explanation of theme: & $\begin{array}{l}\text { Coping strategies and description of how to } \\
\text { adapt to changes }\end{array}$ \\
Data from interviews: & "It's a matter of living as usual. Doing as \\
& much as possible in the way we usually do". \\
\hline
\end{tabular}

\section{Phase 3. Authentication of themes through expert groups of people with dementia and carers}

Consultation meetings with people with dementia and carers took place after analysis of data and after themes had been confirmed, revised or added in accordance to the findings from the interviews. In order to increase transferability to a UK context, consultation meetings were held both in Norrköping, Sweden and Manchester, UK (see the feasibility trial of the "Living Life and Doing things Together" study, outlined earlier). In Sweden, consultation meetings were held with a total of 40 people recruited from an Alzheimer café for people with dementia and carers, a center for carers and at a book café for couples where one partner has a diagnosis of dementia. In Manchester, consultation meetings were held with a group consisting of six couples where one partner has a diagnosis of dementia. The objectives of the meetings were to use the themes as sensitizing concepts that were tested for empirical validity, and with potential to discover 
additional themes of importance for people with dementia and partners.

\section{Ethical considerations}

Participants in the study received relevant oral and written information about the study and that they could withdraw from the study without declaring any reason. Written and verbal consent was collected from people with dementia and partners and all data were kept confidential (World Medical Association, 2016). Despite the information of voluntary participation, underlying power structure within the relationship may influence choice (Braybrook, Mróz, Robertson, White \& Milnes, 2017). It is therefore important that the researcher is responsive and applies a "process consent" method (Hellström, Nolan, Nordenfeldt \& Lundh, 2007), whereby the researcher enables participants to make informed decision from the point of initial contact to completion of the study (Dewing, 2008). The study was given ethical approval by the Regional Ethical Review Board in Linköping and assigned the following code: 2014/419-31. Interviews with participants and meetings with members of the consultation groups were guided by the core principles for involving people with dementia in research (Scottish Dementia Working Group, 2014). The benefits of collaborative research have shown to contribute to participants' sense of purpose, satisfaction and to increased knowledge and self-confidence (Littlechild, Tanner \& Hall, 2015). After the interviews, participants received information about the progress of the study by letter and telephone calls in order to ensure that they were being involved and valued throughout the process.

\section{Findings}

\section{Confirmed themes of the framework}


The deductive analysis, in which the template of themes was applied to the interview data, confirmed the relevance of the pre-determined themes of the draft framework.

\section{Home and neighborhood}

Couples described their home as an important place where they wished to stay as long as possible. Home was perceived as a place of peace, safety and relaxation. Safety was both physical and psychological. Safety inside home was described in concrete physical safety rather than psychological, as actions undertaken to increase security, comfort and independence inside the home. The psychological meaning of home was referred to as a place representing peace, wellbeing and familiarity:

"Ifeel peace and harmony in my home. We like to go out as well, but there's nothing better than coming home when you've been out, closing the door behind us and just relax"

It was not just the home (e.g. house, apartment) that participants described of importance. Relationships with neighbors in the neighborhood, and the sense of having support of each other in everyday life played an important role and contributed to sense of security. Getting out and about in the neighborhood was important to couples and they described the importance of a familiar environment:

"We have lived here so long. Here, I can move about freely. We know the people who live in the area, so you know how you stand, you could say."

For two couples it was no problem for the partner with dementia to take walks relative far away from home, provided that there was a route they had walked many times before. 
One partner with dementia took three hour-long walks around town and one partner with
dementia walked to their allotment everyday.
Meaningful activities and relationships

Keeping involved in everyday activities and social activities were confirmed to be of great importance. Physical activity, most commonly by taking walks, was an activity that most couples enjoyed to do together. Couples had routines of taking walks together and sometimes individually and they described various benefits from being active, such as improved sleep, mood and cognition:

"Yesterday, my partner came home from a long walk with some lovely coffee bread and a bouquet of flowers for me. It was the first time in a long time. I think maybe the endorphins that get activated influence the brain and make my partner less ill. The exercise makes my partner feel better, instead of lying about at home and becoming weary and forgetful"”.

Couples described various ways of mental exercise, but not very often with the aim of improve cognition. They described it in terms of leisure on an everyday basis that was integrated in their interaction "We talk to each other a lot... and we read weekly magazines, and daily newspapers...long and well'. One partner with dementia used to play the piano to keep the brain active "Of course I notice I'm not as good at playing, but it is important for me to maintain the ability”.

Couples confirmed the importance of meeting peers but none of the couples has had the opportunity to do so. They described such an opportunity in terms of feelings of belonging and being understood. The couple in which the partner with dementia attended 
a day centre described that it had become a very important social world with new relationships where the partner with dementia could be herself:

"We would love to meet other couples, but we haven't had the opportunity. I see how good the day center is for my partner. A similar environment, where both can participate, would be good".

\section{Approach and empowerment}

Informing others about having dementia was natural and empowering for couples. Informing others contributed to reduced stress due to not having to cover up symptoms and contributed to conditions for other people to be supportive and understanding. One reason for informing others was to fight the stigma related to dementia:

"We have been very open about it, always. It is nothing to be ashamed of. I can't help it. It has become much more accepted".

On the other hand, meeting with people, in particular new people could create stress due to insecurity, "I get stressed by being so unsure of myself. I can't find the right word and forget things".

In order to reduce stress and feelings of insecurity couples adapted to their situation by choosing which people to socialize with, by adapting activity to capability, and helping each other out in order to keep partaking in valuable activities:

"We plan activities that allow my partner to participate without feeling responsible, because pressure just causes a loss of initiative”. 
The theme "future and planning" were changed in terms of the significance and the subjective meaning for the couples. As described in the rationale (table 1), the theme was initially directed towards planning ahead for future impact of the condition, such as learning more about dementia, talking things through about the person with dementia's preferences and desires in the event that he or she would not be able to express it in the future. The meaning of "future and planning" for the couples in this study did not mean the same; for instance, all couples described that they avoided thinking about the future by living day by day and by making the most of the situation:

"It's difficult to plan for an uncertain future. We believe it will become obvious as the disease develops. It is probably a conscious strategy to live from day to day. There is no point in wallowing in misery, because it will come on its own, if it comes”.

It became obvious that the couples strived to live in the present, they saw no point in wasting their valuable time together worrying about the future. However, sometimes they couldn't help thinking about how it will be in the future "but of course there are some things that worry me, when I cannot sleep you know...".

\section{Couplehood}

Couples spent a lot of time together, sharing chores and activities. It did not mean that they necessarily did the same thing but they were near each other. For example, one couple described that one of them used to cut the grass while the other raked. Couples also tried new things and took actions when they felt under stimulated:

"When things get dull at home, we usually think of something to do. We might go out and eat on an outing. We dress up and eat out. Hanging out at home with nothing to do has a 
negative effect on the brain. We see that clearly after a few days".

Couples described the balance between being as active and independent as possible but still needing support to some extent. It could be a challenge for both partners as articulated by one partner with dementia "I need to feel we are on the same level. I don't want a pat on the head and a compliment on how obedient I've been". Support could also be in terms of reassurance, not just actions:

"It's a relief to have in the background, someone who knows how things usually are, and how they used to be. But that's what it's all about: supporting and encouraging each other. So, it's not so strange".

Communication and interaction was an additional theme that was confirmed but changed in terms of the significance. The pre-determined theme "communication" was initially directed towards support strategies to facilitate communication between spouses, e.g. by using reminiscence strategies. Couples in this study described that they did not use these strategies "yet", which indicated that they might not need to use them yet. One couple thus said that they sometimes look at photos in their album but not more than other people do. The same couple said, "We are not spending our time trying to remember things, because that is the problem, to remember...". The meaning of the theme "communication" was instead described as spending time together and to interact in various ways. For one couple, the significance of their communication had changed, as described by the partner "What we say is not as important as how we say it", indicating that it is of great importance with a friendly atmosphere.

\section{Additional themes}


The inductive analysis of interview data resulted in three additional themes "socializing with family and friends" "state of mind and living as usual" and "being a comfort and a friend".

Couples described wellbeing in meeting their friends and family. Meeting with familiar people instead of new people could reduce the stress of socializing, which in turn also contributed to less noticeable dementia symptoms. One couple described that it was very important for the partner with dementia to continue attending the monthly seniorcenter meetings. She had always been in charge of buying and serving the refreshments and for her to keep seeing her friends, and also to continue her role in the refreshments, her partner helped her by driving to the location and supported her making the coffee and setting the table. Socializing with friends and family was also described challenging due to some friends and family being overly helpful. One couple had chosen to stop seeing friends that did not contribute to their wellbeing:

“We've chosen to stop seeing a couple of friends. One was so overly helpful and wanted to "take care of" so much it became offensive. It's sad, but we have to socialize with people who make us feel good".

The added theme "State of mind/living as usual" emerged as a result of the changed significance of the theme "future and planning" as it was evident that couples strived to live as normal lives as possible, take one day at a time and to sustain positivity in their lives, as these two quotations illustrate:

"I don't feel sick. Of course, there are some difficulties, but we are living as we always have". 
"I feel it is important to try to behave as usual and not be thinking, "I can't do this, and I can't do that... not just sit at home and withdraw into oneself and think about how old and sick one is. I think that is dangerous".

Sustaining positivity, and a positive state of mind was also described as something couples could chose to some extent, by seeing the good before the bad and not worry about trivial things that used to worry them. Keeping a positive spirit was something couples worked on continually:

"We decided to not be that kind of discontented people but instead would take responsibility for finding fun things. We believe it is possible for us to choose the mood to some extent. It is not worthwhile to get angry over a bit of dust here and there. There are more important things".

The theme "being a comfort and a friend" represented partners giving each other comfort and support when they felt sad. The most important component in comforting was closeness, hugs and touch:

"Sometimes I need some extra comfort, when I am sad, and I wonder how things will be. I get angry at everything, but then my partner comes and holds me, and then it usually gets better. Sometimes just a little bit of strength is needed like that".

Both partners comforted each other, even in really difficult moments. One partner was worried about if he should die before his wife with dementia and said "Who is going to care for you then"? His partner with dementia comforted him by saying that he should not think of that "we will handle that then, if it turns out like that". 


\section{Subtheme added through consultation groups}

The accuracy of the confirmed themes and the added themes were discussed in the consultation groups of people with dementia and carers in Sweden and in UK. Field notes were taken during the consultation meetings that confirmed all the themes accuracy, and also resulted in a new theme "intimacy". The discussion about intimacy occurred in relation to couplehood. Several members described, in particular the partners, that physical closeness and sexual intimacy had become problematic in their relationship. One carer, whose partner with dementia recently had moved to a special accommodation, described a dramatic change in her relationship with her husband, from the couple being physical and cuddly, to her husband laying at the edge of the bed, risking to fall down on the floor, just to avoid being close to her. Another aspect of sexuality came from a man who was highlighting the issue of consent; how could he be sure that his wife with dementia gave her consent to their sexual activities?

\section{Summary - revision of the framework}

Findings of the interviews and from the consultation meetings required modifications of the draft framework. The confirmed themes and added themes were connected into the four main themes; "Home and Neighborhood", "Meaningful Activities and Relationships", "Approach and Empowerment" and "Couplehood" with corresponding sub themes. The revised framework with confirmed themes and added themes is displayed in figure 1. 


\section{Approach and Empowerment}

Adapting activity to capability

State of mind and living as usual

Future and planning

Informing others

Stress

\section{Meaningful Activities and}

Relationships

The meaning of home

Comfort and safety

Socialising with family and friends
Physical wellbeing

Mental wellbeing

Individual activities

Meeting with peers

Content of

"DemPower"

\section{Couplehood}

Doing things together

Being a comfort and a friend

Being active and supportive

Communication and interaction

Avoiding conflicts

Intimacy

Figure 1. Revised framework of the self-management guide

\section{Discussion}

The aim of this study was to identify relevant content for a self-management guide aimed at couples where one partner has a diagnosis of dementia. To the best of our knowledge, no previous self-management support has been developed that targets the couple as a unit, for couples to engage in as a dyad without professionals present, and which addresses the couples' relationship in the context of everyday life. The people with dementia who participated in this study received their dementia diagnosis between three to eight years ago. However, we do not consider that the time for diagnosis is a good measure of how long a person has lived with dementia. The person who was diagnosed three years ago may have lived with the condition longer, and at the time for the interviews, with a more severe dementia than the person diagnosed eight years ago. We 
believe that the themes of the self-management guide and the self-management approach can be used from mild dementia to later stages, even though the partner may need to take more responsibility and initiative for the activities to be carried out and adjusted to suit the current situation and the couple. Being a couple - and sense of couplehood - is not dependent on gender and can therefore be applied to any dyad who are partners and live in a couple-based relationship.

The findings of this study highlight four main themes of importance for people with dementia and partners: "Home and Neighborhood", "Meaningful Activities and Relationships", “Approach and Empowerment” and 'Couplehood'. Not surprisingly, these four main themes cover most aspects of well being for people in general; most people wish to feel safe and loved, be able to live in their own home, to be included in social life, to live as independent as possible, to have a meaningful everyday life with their family and friends, and to live as 'normal' a life as possible (WHO, 2018). According to the findings of our study, areas of potential challenge for couples with dementia were related to these universal aspects of wellbeing and where therefore present in the context of everyday life.

The findings of this study suggest that "living as usual" and to "normalize" was an important aspect of wellbeing, and also an important coping strategy used by the couples. These findings are in line with previous research (McRae, 2011; van Nes, Jonsson, Abma \& Deeg, 2013; Genoe \& Dupuis, 2014; Torrington, 2009) and further imply that couples, where one partner has a diagnosis of dementia, need to be supported in the context of an everyday normal life. Self-management support targeting the everyday, therefore, may be an important aspect in such a care approach. Furthermore, as 
highlighted above, what contributes to wellbeing for couples where one partner has a diagnosis of dementia should be the same for couples in general. Normalizing the needs of people with dementia and partners may therefore be of particular importance in order to spread greater understanding among the general population and for communities to pay attention to, and act upon the needs of people with dementia (and partners) to a higher extent.

\section{Targets and topics of self-management in dementia}

A review of self-management for people with dementia indicated that self-management in dementia often involve carers and/or partners but are carried out as group support (Quinn, Toms, Anderson \& Clare, 2016), thus contributing to limits for a couplehood approach. However, the main findings of our study are in line with previous research of self-management in dementia, several of our identified topics can be found in recent studies, for example; relationships, coping, communication, physical and psychological wellbeing, meaningful activities and planning for the future (Sprange, Mountain, Shortland, Craig, Blackburn \& Bowie et al. 2015; Mountain \& Craig, 2012; Martin, Turner, Wallace, Stanley, Jesuthasan \& Bradbury, 2015; Quinn, Toms, Jones, Brand, Edwards \& Sanders et al. 2016). The latter, "planning for the future", seems to be a recurring topic within self-management for people with dementia and often involves learning about dementia and planning for future impacts (Quinn et al. 2016a). However, there are significant differences in how couples with dementia choses to cope with thoughts about the future. In Hellström and Torres' (2013) study, most participants wanted to know and learn about the condition in order to be prepared for the future, whilst other studies, including the present one, revealed that couples where one partner 
has a diagnosis of dementia often handle their situation by living in the present and taking one day at a time (McRae, 2010; Hellström et al. 2007; Hellström \& Torres, 2016). In the literature, learning about dementia seems to be perceived as either helpful, or depressing and limiting, by couples where one partner has a diagnosis of dementia (Robinson et al. 2015; Grand et al. 2011; Hellström \& Torres, 2016 McRae, 2010; Hellström et al. 2007).

The reason for feeling depressed and limited may due to couples being "convinced" that the progression of the dementia will be in line with the "bleak prognosis" as described in literature rather than embracing the fact that symptoms, and manifestations, of dementia differ widely (Mountain, 2006; Pearlin, Harrington, Lawton, Montgomery \& Zarit, 2001). This does not only raise questions about how information about dementia and its content is delivered, could it also be that researchers and health care professionals have taken precedence in the interpretation of what people with dementia and partners need in order to manage their future? The key may be to identify couples coping strategies prior to an intervention(s) in order to support their way of handling their situation and to not impose "lessons" which could lead to negative outcomes.

The sexual aspect of intimacy was not included within the predetermined framework of themes in this study, which in retrospect may seem as a limitation. The reason why the topic "sexuality" was not recurring in the literature search prior to this study may due to the salutogenic approach that our study is based upon, while most of the research conducted within the topic is problem-based (e.g. hyper sexuality) (Bauer, Nay, Tarzia, Fetherstonhaugh, Wellman \& Beattie, 2014; Youell, Callaghan, Buchanan, 2016). Additionally, when the subject occurred during consultation meetings, it was in relation 
to problems, which indicates that the subject may be unsuitable to include in a selfmanagement guide that couples engage in without the presence of a professional. An additional reason for sexuality being overlooked may due to the sparse research regarding lived experiences of sex and intimacy in dementia (Youell et al. 2016). However, the theme "Being a comfort and a friend" in this study, included intimacy like touch, closeness and togetherness which are important aspects of relationships in dementia, as it becomes a source of extended communication in the context of everyday life, described by (Youell et al. 2016, p. 954) as "embodied day-to-day-ness of living together, of shared relational spaces". Nevertheless, the discussions in the consultation groups in this study indicated that sexuality could be a problem, and that it should be addressed to a greater extent in research.

\section{Challenging the traditional views and approaches of self- management}

Self-management aimed at people with dementia is controversial. Martin, Turner, Wallace, Choudhry and Bradbury (2013) found that barriers to self-management lie on multiple levels; among people with dementia, carers, health care professionals and the general public. The most prominent barriers seem to be a deficit focus, lack of services with a positive and enabling approach, and the view of people with dementia as passive recipients of care. Martin et al. (2013a), found that skepticism towards the benefits of self-management was evident among carers and health care professionals, but not among people with dementia. In addition, perceived barriers to self-management among people with dementia included worries, fears and lack of confidence, which may be a reflection of the overall negative view of self-management for people with dementia. Thus, there is 
an imminent risk of a negative spiral of disempowerment; how should people with dementia believe in their own abilities when no one else does?

On the other hand, there is a growing interest for self-management in dementia, and the views of people with dementia being unable to learn new skills are being challenged (Mountain, 2006). The small number of studies being conducted in the area has shown promising results for participant's general wellbeing and sense of self-efficacy (see for example Quinn et al. 2016b; Sprange et al. 2015; Hickman, Wiersma \& Harvey, 2015; Laakkonen, Kautiainen, Hölttä, Saivikko, Tilvis \& Strandberg et al. 2016). Furthermore, the traditional approach of self-management may also need to be challenged in order for self-management to be successfully applied for people with dementia. For example, self-management is often highly related to the management of symptoms of the condition, and based on people's perceived problems (Lorig \& Holmen, 2003). Our findings of this study suggest that, in line with Martin et al. (2013), self-management for people with dementia should promote positive and meaningful experiences and emphasize managing everyday life rather than managing the dementia itself. We therefore consider that a self-management guide can help couples to make "valueorientations" which can support them in finding and utilizing their positive resources and strengths, which in turn may contribute to higher sense of meaningfulness.

Hickman et al. (2015) found that the three core skills for self-management in dementia should focus on "adapting to change", "finding meaning and purpose" and "communication". These core skills can be found in several of our themes, for example in "adapting activity to capability", "meaningful activities and relationships" and "communication and interaction", and seem to be suitable goals for self-management in 
dementia, when problem based and disease specific issues may not be applicable. Another important aspect of self-management for people with dementia would be easy access. According to the review conducted by Quinn et al. (2016a) and the review of Bielsten \& Hellström (2017b), self-management interventions for people with dementia are dependent on the delivery of professionals and on particular locations, which leads to various limits such as limited access and wider dissemination. Given that the number of couples where one partner has a diagnosis of dementia will increase in the coming years, there is a need for support that are not solely dependent on resources in health care. Easy accessible self-management tools thus have the potential of positive impact for couples where one partner has a diagnosis of dementia, and could also contribute to less strain on community resources.

\section{Trustworthiness}

According to Schutz (1973), second order constructs gain trustworthiness through the three postulates logical consistency, subjective interpretation and adequacy. Our literature search of previous research, the anchoring of our findings in research, and our emphasis on "normality" reflects the logical consistency of our findings. The interviews with couples, where one partner has a diagnosis of dementia, enabled the gathering of first order information, i.e. from people with lived experience and with subjective interpretation. The interview format "dyadic interviewing" also enabled getting closer to lived experience, as the presence of an additional person living in the situation served as back up or reliability check. The risk of imposing the researcher's perspectives or biases was also reduced when the focus lied on the dialogue between the couple. Moreover, dyadic interviewing enables partners to support each other and also prompt each other in 
the dialogue, facilitating for the person with dementia to share his/her experiences (Sohier, 1995). An example of this was when the partner further grounded the theme and the trigger in the couple's own experiences, for example by saying, "when we do things like going to the cinema and restaurants". This enabled the person with dementia to share experiences. On the other hand, there is a risk that dyadic interviewing contributes to limitations due to the potential of partners not being able to speak freely in front of their partner. Dyadic interviewing could therefore result in fragmented data, if both partners do not have an equal voice (Zahrin, 2018).

Regarding the third postulate, the need for adequacy, this was achieved by arriving at consensus in the consultation groups, in which the subjective meaning of the theme was verified as being successfully maintained and thereby strengthening credibility. The hybrid approach of deductive and inductive analysis facilitated the process in following Schutz (1973) postulates for trustworthiness, and also supported the process of our collaborative research with and for couples with dementia. Collaborative research has shown to be an effective method to identify and select themes relevant to the target group, and has the potential to enhance understanding of data (Littlechild et al. 2015).

\section{Conclusion}

The findings of this study highlight the importance for couples where one partner has a diagnosis of dementia to be enabled to live as normal lives as possible in the context of everyday life. The needs of couples where one partner has a diagnosis of dementia are no different from the needs of couples in general who wish to be recognized and valued by each other, as a couple and by the local community. This study also addresses the 
importance of recognizing the strengths and resources of people with dementia and their partners in order for them to be empowered instead of disempowered. We have emphasized and confirmed the normal needs of people with dementia and partners, which in turn may contribute to reduced stigma and a higher understanding of the needs of couples where one partner has a diagnosis of dementia. The framework of themes developed in this study cover the major areas "Home and Neighborhood", "Meaningful Activities and Relationships", "Approach and Empowerment" and "Couplehood" of wellbeing. Couples need for support is of course not present in all areas. A selfmanagement tool could therefore serve as a guide for couples in order for them to focus on the parts that they consider beneficial for their situation. There is also a potential that a framework of themes could serve as a guide for health care professionals in identifying areas, in which couples with dementia may need support. Developing and modifying our framework into an assessment tool could therefore be of interest for further research.

\section{Conflict of interest}

The authors declare no conflicts of interest.

\section{Funding}

The support of the Economic and Social Research Council (ESRC) and National Institute for Health Research (NIHR) is gratefully acknowledged. This work forms part of the ESRC/NIHR Neighbourhoods and Dementia mixed methods study [www.neighbourhood sanddementia.org], specifically work program 6 . 


\section{References}

Ablitt, A., Jones, G.V., \& Muers, J. (2009). Living with dementia: A systematic review of the influence of relationship factors. Aging \& Mental Health, 13, 497-511, doi: 10.1080/13607860902774436.

Alzheimer's Association. I Have Alzheimer's Disease - Sharing Your Diagnosis. Available at: http://www.alz.org/i-have-alz/sharing-your-diagnosis.asp.

Alzheimer's Association. Reducing Stress. Available at: http://www.alz.org/i-havealz/reducing-stress.asp - tips.

Antonovsky A. (1979). Health, Stress, and Coping. New Perspectives on Mental and Physical Well - Being. Jossey Bass, San Francisco.

Antonovsky A. (1987). Unraveling the Mystery of Health: How People Manage Stress and Stay Well. Jossey-Bass, San Francisco.

Balfour, A. (2014). Developing therapeutic couple work in dementia care - the living together with dementia project. Psychoanalytic Psychotherapy, 28, 304-320, doi: $10.1080 / 02668734.2014 .934524$.

Barlow, J., Wright, C., Sheasby, J., Turner, A., \& Hainsworth, J. (2002). Selfmanagement approaches for people with chronic conditions: a review. Patient Education And Counseling, 48, 177-187, doi: 10.1016/S0738-3991(02)00032-0.

Bartlett, R. (2012). Modifying the diary interview method to research the lives of people with dementia. Qualitiative Health Research, 22, 1717-1726, doi: $10.1177 / 1049732312462240$.

Bauer, M., Nay, R., Tarzia, L., Fetherstonhaugh, D., Wellman, D., \& Beattie, E. (2014). "We need to know what's going on": Views of family members toward the sexual expression of people with dementia in residential aged care. Dementia, 13, 571585, doi: 10.1177/1471301213479785.

Bergman, M., Graff. C., Eriksdotter, M., Fugl-Meyer, K.S., \& Schuster, M. (2016). The meaning of living close to a person with Alzheimer disease. Med Health Care Philos, 19, 341-349, doi: 10.1007/s11019-016-9696-3. 
Bielsten, T., \& Hellström, I. (2017a). A review of couple-centred interventions in dementia: Exploring the what and why - Part A. Dementia (London, England), doi:10.1177/1471301217737662.

Bielsten, T., \& Hellström, I. (2017b). An extended review of couple-centred interventions in dementia: Exploring the what and why - Part B. Dementia (London, England), doi: $10.1177 / 1471301217737653$.

Boots, L. M., de Vugt, M. E., Withagen, H. E., Kempen, G. I., \& Verhey, F. R. (2016). Development and Initial Evaluation of the Web-Based Self-Management Program "Partner in Balance" for Family Caregivers of People With Early Stage Dementia: An Exploratory Mixed-Methods Study. JMIR Research Protocols, 5, doi: 10.2196/resprot.5142.

Bowes, A., Dawson, A., Jepson, R., \& McCabe, L. (2013). Physical activity for people with dementia: a scoping study. BMC Geriatrics, 13, doi: 10.1186/1471-2318-13129.

Braybrook, D., Mróz, L., Robertson, S., White, A., \& Milnes, K. (2017). Holistic Experiences and Strategies for Conducting Research with Couples. Qualitative Health Research, 27, 584-590, doi: 10.1177/1049732316628520.

Brodaty, H., Gresham, M., \& Luscome, G. (1997). The Prince Henry Hospital dementia caregivers training programme. International Journal of Geriatric Psychiatry, 12 , 183 - 193, doi: 10.1002/(SICI)1099-1166(199702)12:2<183

Brodaty, H., \& Donkin, M. (2009). Family caregivers of people with dementia. Dialogues In Clinical Neuroscience, 11, 217-228, PMCID: PMC3181916.

Clare L., Rowlands J. M., \& Quin, R. (2008). Collective strength: the impact of developing a shared social identity in early-stage dementia. Dementia 7, 9-30, doi: 10.1177/1471301207085365.

Clare,L., Nelis, S.H., Whitaker, C.J., Martyr, A., Markova, I. S., Roth, I., Woods, R.T. \& Morris, R.G. (2012). Marital Relationship Quality in Early-Stage dementia Perspectives From People With Dementia and Their Spouses. Alzheimer Disease and Associated Disorders, 26, 148-158, doi: 10.1097/WAD.0b013e318221ba23.

Dal Bello-Haas, V. M., O’Connell, M. E., Morgan, D. G., \& Crossley, M. (2014). Lessons learned: feasibility and acceptability of a telehealth-delivered exercise 
intervention for rural- dwelling individuals with dementia and their caregivers. Rural \& Remote Health, 14, 1-11, PMID: 25081991.

Department of Health. (2012). Prime Minister's challenge on dementia: Delivering major improvements in dementia care and research by 2015. London: Department of Health.

(www.gov.uk/government/uploads/system/uploads/attachment_data/file/215101/d h 133176.pdf)

Dewing, J. (2008). Process consent and research with older persons living with dementia. Research Ethics Review, 4, 59-64, doi: 10.1177/174701610800400205.

Duggan, S., Blackman, T., Martyr, A., \& Van Shaik, P. (2008). The impact of early dementia on outdoor life A shrinking world'? Dementia, 7, 191-204, doi: $10.1177 / 1471301208091158$.

Fereday, J., \& Muir-Cochrane, E. (2006). 'Demonstrating Rigor Using Thematic Analysis: A Hybrid Approach of Inductive and Deductive Coding and Theme Development', International Journal Of Qualitative Methods, 5, 1-11, doi: $10.1177 / 160940690600500107$.

Grand, J., MacDonald, S. \& Caspar, S. (2011). Clinical features and multidiciplinary approaches to dementia care. Journal Of Multidiciplinary Healthcare, 4, 125-147, doi: 10.2147/JMDH.S17773.

Genoe, M., \& Dupuis, S. (2014). The role of leisure within the dementia context. Dementia, 13, 33-58, doi: 10.1177/1471301212447028.

Gillsjö, C., Schwartz-Barcott, D., \& von Post, I. (2011). Home: The place the older adult can not imagine living without. MC Geriatrics, 1, doi:10.1186/1471-2318-11-10.

Groat, A., \& Weems, M. (2009). Interests and activities toolkit for use with people with dementia - A guide for staff and carers. NHS Dumfries \& Galloway.

Hellström, I., Nolan, M., \& Lundh, U. (2005) 'We do things together': A case study of 'couplehood' in dementia. Dementia: The International Journal of Social Research and Practice, 4, 7-22, doi: 10.1177/1471301205049188.

Hellström, I., Nolan, M., \& Lundh, U. (2007) Sustaining 'couplehood': Spouses strategies for living positively with dementia. Dementia, 6, 383-409, doi: $10.1177 / 1471301205049188$. 
Hellström, I., Nolan, M., Nordenfeldt, L., \& Lundh, U. (2007). Ethical and methodological issues in interviewing persons with dementia. Nursing Ethics, 2007. 14, 608-619, doi: 10.1177/0969733007080206.

Hellström, I., \& Torres, S. (2013). A wish to know but not always tell - couples living with dementia talk about disclosure preferences. Aging \& Mental Health, 17, 157167, doi: 10.1080/13607863.2012.742491.

Hellström, I., \& Torres, S. (2016) The "not yet" horizon: Understandings of the future amongst couples living with dementia. Dementia, 15: 1562-1585, doi: $10.1177 / 1471301214565673$.

Hernández, S.S., Sandreschi, PF., Da Silva, FC., Arancibia, BV., da Silva, R., Gutierre, PB., \& Andrade, A. (2015). What are the benefits of exercise for Alzheimer's disease? A systematic review of the past 10 years. Journal Of Aging And Physical Activity, 23, 659-668, doi: 10.1123/japa.2014-0180.

Hickman, K., Wiersma, E., \& Harvey, D. (2015). Taking control of our lives: Developing a self-management program for people living with dementia through meaningful engagement of people living with dementia. Alzheimer's \& Dementia: The Journal Of The Alzheimer's Association, 11, 191-192, doi: 10.1016/j.jalz.2015.07.173.

Hill, T.M., Loren Mowszowski, D., Sharon, L., Naismith, D., Verity, L., Chadwick, B., Michael Valenzuela, P., \& Amit Lampit, P. (2017). Computerized Cognitive Training in Older Adults With Mild Cognitive Impairment or Dementia: A systematic review and Meta-Analysis. American Journal Of Psychiatry, 4, doi: 10.1176/appi.ajp.2016.16030360.

Ingebretsen, R., \& Solem, P.E. (1998). Spouses of persons with dementia: Attachment, loss and coping. Norwegian Journal of Epidemiology 8, 149-156, doi: 10.5324/nje.v8i2.457.

Ingersoll-Dayton, B., Spencer, B., Kwak, M., Scherrer,K., Allen, R. S., \& Campbell, R. (2013). The Couples Life Story Approach: A Dyadic Intervention for Dementia. Journal of Gerontological Social Work, 56, 237-254, doi: 10.1080/01634372.2012.758214. 
Keady, J., \& Nolan, M. (2003). The dynamics of dementia: Working together, working separately, or working alone. Partnerships in family care, 2003, 15-32.

Keady, J., Campbell, S, Barnes., Ward, R., Li, X., Swarbrick, C. \& Elvish, R. (2012). Neighbourhoods and dementia in the health and social care context: A realist review of the literature and implications for UK policy development. Reviews In Clinical Gerontology, 22, 150-163, doi: 10.1017/S0959259811000268.

Keady, J. (2014). Neighbourhoods and dementia. Journal of Dementia Care, 22, 16-17. Keyes, S.E., Clarke, C.L., Wilkinson, H., Alexiuk, E.J., Wilcockson, J., Robinson, L., \& Cattan, M. (2016). "We're all thrown in the same boat...”: A qualitative analysis of peer support in dementia care. Dementia, 15, 560-577, doi: $10.1177 / 1471301214529575$.

Lamotte, G., Shah, R.C., Lazaroy, O., \& Corcos, DM. (2017). Exercise training for persons with Alzheimer's disease and caregivers: A review of dyadic exercise interventions. Journal Of Motor Behavior, 49, 365-377, doi:

10.1080/00222895.2016.1241739.

Laakkonen, M., Kautiainen, H., Höltää, E., Tilvis, R.S., Strandberg, T.E., \& Pitkälä, K.H. (2016). Effects of self-management groups for people with dementia and their spouses - Randomized controlled trial. Journal Of The American Geriatrics Society, 64, 752-760, doi: 10.1111/jgs.14055.

Leung, P., Orell, M., \& Orgeta, V. (2015). Social support group interventions in people with dementia and mild cognitive impairment: a systematic review of the literature. International Journal Of Geriatric Psychiatry, 30, 1-9, doi: $10.1002 / \mathrm{gps} .4166$.

Lillekroken, D., Slettebœ, A., \& Hauge, S. (2015). Enabling resources in people with dementia: A qualitative study about nurses'strategies that may support a sense of coherence in people with dementia. Journal Of Clinical Nursing, 24, 3129-3137, doi: 10.1111/jocn.12945.

Littlechild, R., Tanner, D., \& Hall, K. (2015). Co-research with older people: perspectives on impact. Qual Soc Work, 1418-35, doi: $10.1177 / 1473325014556791$. 
Lorig, K., \& Holman, H. (2003). Self-management education: history, definition, outcomes, and mechanisms. Annals of Behavioral Medicine, 26, 1-7, doi: 10.1207/S15324796ABM2601_01.

McGovern, J. (2011). Couple Meaning-Making and Dementia: Challenges to the Deficit Model. Journal of Gerontological Social Work, 54. 678-690, doi: 10.1080/01634372.2011.593021.

Martin, F., Turner, A., Wallace, L., M., Choudhry, K., \& Bradbury, N. (2013a). Perceived barriers to self-management for people with dementia in the early stages. Dementia, 12, 1-13, doi: 10.1177/1471301211434677.

Martin, F., Turner, A., Wallace, L. M., \& Bradbury, N. (2013b). Conceptualisation of self-management intervention for people with early stage dementia. European Journal of Ageing, 10, 75-87, doi: 10.1007/s10433-012-0253-5.

Martin, F., Turner, A., Wallace, LM., Stanley, D., Jesuthasan, J., \& Bradbury, N. (2015). Qualitative evaluation of a self-management intervention for people in early stage dementia. Dementia, 14, 418-435, doi: 10.1177/1471301213498387.

Martire, L.M., Schulz, R., Helgeson, V.S., Small, B.J., \& Saghafi., E.M. (2010). Review and meta-analysis of couple-oriented interventions for chronic illness. Annals of Behavior Medicine, 40, 325-342, doi: 10.1007/s12160-010-9216-2.

McGovern, J. (2015). Living Better With Dementia: Strengths-Based Social Work Practice and Dementia Care. Social Work In Health Care, 54, 408, doi: 10.1080/00981389.2015.1029661.

McRae, H. (2009). "Making the best you can of it": living with early-stage Alzheimer's disease. Sociology Of Health \& Illness, 30, 396-412, doi: 10.1111/j.14679566.2007.01056.x.

McRae, H. (2011). Self and other: The importance of social interaction and social relationships in shaping the experience of early-stage Alzheimer's disease. Journal Of Aging Studies, 25, 445-456, doi: 10.1016/j.jaging.2011.06.001. Merrick, K. Camic, P., \& O’Shaughnessy, M. (2016). Couples constructing their experiences of dementia: A relational perspective', Dementia, 15, 34-50, doi: $10.1177 / 1471301213513029$. 
Mondini, S., Madella, I., Bigolin, A., Tomasi, C., Michieletto, M., \& Mapelli, D. (2016). Cognitive reserve in dementia: Implications for cognitive training. Frontiers In Aging Neuroscience, 8, doi: 10.3389/fnagi.2016.00084.

Moon, H., \& Adams, K. (2012). The effectiveness of dyadic interventions for people with dementia and their caregivers. Dementia, 12, 821-839, doi: $10.1177 / 1471301212447026$.

Mountain, G. (2006). Self management and dementia: An exploration of concepts and evidence. Dementia: The International Journal of Social Research and Practice, 5, 429-447, doi: 10.1177/1471301206067117.

Mountain, G., \& Craig, C. (2012). What should be in a self-management programme for people with dementia? Aging \& Mental Health, 16, 576-583, doi:

10.1080/13607863.2011.651430.

Norton, M.C., Piercy, K.W., Rabins, P.C., Green, R.C., Breitner, J.C.S., Ostbye, T., Corcoran, C., Welsh- Bohmer, K.M., Lykefsos, C.G., \& Tschanz, J.T. (2009). Caregiver-Recipient Closeness and Symptom Progression in Alzheimer's Disease. The Cache County Dementia Progression Study. Journal of Gerontology: Psychological Sciences, 64B, 560-568, doi: 10.1093/geronb/gbp052.

Nygård, L. (2004). Responses of persons with dementia to challenges in daily activities: A synthesis of findings from empirical studies. American Journal of Occupational Therapy, 58, 435-445, doi: 10.5014/ajot.58.4.435.

Osman, S.E., Tischler, V., \& Schneider, J. (2016). Singing for the brain: A qualitative study exploring the health and well-being benefits of singing for people with dementia and their carers. Dementia: The International Journal Of Social Research And Practice, 15, 1326-1339, doi: 10.1177/1471301214556291.

Pearlin, LI., Harrington, C., Lawton, MP., Montgomery, RJ., \& Zarit, SH. (2001). An overview of the social and behavioral consequences of Alzheimer's disease. Aging \& Mental Health, 5, 3-6, doi: 10.1080/713650012.

Pitkala. KH., Raivio, MM., Laakkonen M-L, Tilvis, RS., Kautiainen, H., \& Strandberg TE. (2010). Exercise rehabilitation on home-dwelling patients with Alzheimer's disease - a randomized, controlled trial. Study protocol. Trial,s 11, 92-92, doi:10.1186/1745-6215-11-92. 
Purkis, M., \& Ceci, C. (2015). Problematising care burden research. Ageing And Society, 35, 1410-1428, doi: 10.1017/S0144686X14000269.

Quinn, C., Clare, L., Pearce, A., \& van Dijkhuizen, M. (2008). The experience of providing care in the early stages of dementia: An interpretative phenomenological analysis. Aging \& Mental Health, 12, 769-778, doi: 10.1080/13607860802380623.

Quinn, C., Toms, G., Anderson, D., \& Clare, L. (2016a). A Review of Self-Management for People With Dementia and Mild Cognitive Impairment. Journal of Applied Gerontology, 35, 1154-1188, doi: 10.1177/0733464814566852.

Quinn, C., Toms, G., Jones, C,. Brand, A., Edwards R.T., Sanders, F., \& Clare, L. (2016b). A pilot randomized controlled trial of a self-management group intervention for people with early-stage dementia (The SMART study). International Psychogeriatrics, 28, 787-800, doi: 10.1017/S1041610215002094. Reilly, M.C., Relkin, N.R., \& Zbrozek A.S. (2006). Development and Testing of a New Outcome Measure of Relationship Between Patients With Alzheimer's Disease and Their Partners. American Journal of Alzheimer's Disease \& Other Dementias, 21, 249-257, doi: 10.1177/1533317506290665.

Robinson, L., Clare, L., \& Evans, K. (2005). Making sense of dementia and adjusting to loss: Psychological reactions to a diagnosis of dementia in couples. Aging \& Mental Health, 9, 337-347, doi: 10.1080/13607860500114555.

Robinson, L., Tang, E., \& Taylor, J. (2015). Dementia: timely diagnosis and early intervention. Bmi-British Medical Journal, 350, doi: 10.1136/bmj.h3029.

Robinson, C. (2017). Families Living Well with Chronic Illness: The Healing Process of Moving on. Qualitative Health Research, 27, 447-461, doi:10.1177/1049732316675590.

Scottish Dementia Working Group Research Sub-Group, UK. (2014). Core principles for involving people with dementia in research: Innovative practice. Dementia, 13, 680-685, doi: 10.1177/1471301214533255.

Schütz, Alfred \& Luckmann, Thomas. (1973). The Structures of the Life-world. Evanston: Northwestern University Press. 
SCIE. (2015). Planning for the future after a diagnosis of dementia. Available at: http://www.scie.org.uk/dementia/after-diagnosis/support/planning.asp.

Sohier R. (1995). The Dyadic Interview As a Tool for Nursing Research. CLINICAL METHODS, 96-101, doi: 10.1016/S0897-1897(95)80562-1.

Soilemezi, D., Drahota, A., Crossland, J., Stores, R., \& Costall, A. (2017). Exploring the meaning of home for family caregivers of people with dementia. Journal Of Environmental Psychology, 5, 170-181, doi: 10.1016/j.jenvp.2017.03.007.

Solum Myren, G., Enmarker, I., Saur, E., \& Hellzen, O. (2013). Relatives’ experiences of everyday life when receiving day care services for persons with dementia living at home. Health, 5, 1227-1235, doi: 10.4236/health.2013.58166.

Spector, A., Orrell, M., \& Woods, B. (2017). The Evidence-Base. Available at: http://www.cstdementia.com/page/the-evidence-base.

Sprange, K., Mountain, G.A,. Shortland, K., Craig, C., Blackburn, C., Bowie, P., \&...Spencer, M. (2015). Journeying through Dementia, a community-based selfmanagement intervention for people aged 65 years and over: a feasibility study to inform a future trial. Pilot And Feasibility Studies, 42, doi: 10.1186/s40814- 0150039-6.

Spruytte, N., Van Audenhove, C., \& Lammertyn, F. (2001). Predictors of institutionalization of cognitively-impaired elderly cared for by their relatives. International Journal Of Geriatric Psychiatry, 16, 1119-1128, doi: 10.1002/gps.484.

Söderhamn, U., Aasgaard, L., \& Landmark, B. (2014). Attending an activity center: positive experiences of a group of home-dwelling persons with early-stage dementia. Clinical Interventions In Aging, 9, 1923-1931, doi: 10.2147/CIA.S73615.

Tanner, B., Tilse, C., \& de Jonge, D. (2008). Restoring and sustaining home: the impact of home modifications on the meaning of home for older people. Journal of Housing For The Elderly, 22, 195-215. DOI: 10.1080/02763890802232048

Toms, GR., Clare, L., Nixon, J., \& Quinn, C. (2015). A systematic narrative review of support groups for people with dementia. International Psychogeriatrics, 27, 1439-1465, doi: 10.1017/S1041610215000691. 
Torrington, J. (2009). The design of technology and environments to support enjoyable activity for people with dementia. European Journal of Disability Research, 3,123-137, doi: 10.1016/j.alter.2009.01.005.

Van't Leven, N., Prick, A., Groenewoud, J., Roelofs, P., de Lange, J., \& Pot, A.M. (2013). Dyadic interventions for community-dwelling people with dementia and their family caregivers: a systematic review', International Psychogeriatrics, 25, 1581-1603, doi: 10.1017/S1041610213000860.

van Nes, F., Jonsson, H., Abma, T., \& Deeg, D. (2013). Changing everyday activities of couples in late life: Converging and keeping up. Journal Of Aging Studies, 278291, doi: 10.1016/j.jaging.2012.09.002.

Vernooij-Dassen, M., \& Moniz-Cook, E. (2016). Person-centred dementia care: moving beyond caregiving. Aging \& Mental Health, 20, 667-668, doi: 10.1080/13607863.2016.1154017.

Ward, R., Graham, B., Manji, K., Rummery, K., Clark, A., Cambell, S., \& Kullberg, A. (2017). The lived neighbourhood: understanding how people with dementia engage with their local environment. International Psychogeriatrics, 1-14. doi: 10.1017/S1041610217000631.

Wei-Wei, C., Xia, Z., \& Wen-Juan, H. (2016). Role of physical exercise in Alzheimer's disease (Review). Biomedical reports, 4, 403-407, doi: 10.3892/br.2016.607.

Wiles, J.L., Leibing, A., Guberman, N., Reeve, J., \& Allen, R.E. (2012). The meaning of "aging in place" to older people. Gerontologist 52, 357-66, doi: 10.1093/geront/gnr098.

Wherton, J. P., \& Monk, A. F. (2008). Technological opportunities for supporting people with dementia who are living at home. International Journal Of Human Computer Studies, 66571-586, doi: 10.1016/j.ijhcs.2008.03.001.

Woods, R., Bruce, E., Edwards, R., Elvish, R., Hoare, Z., \&... Hounsome, B. (2012). REMCARE: reminiscence groups for people with dementia and their family caregivers - effectiveness and cost-effectiveness pragmatic multicentre randomised trial. Health Technology Assessment, 16, 1-116, doi: 10.3310/hta16480. 
World Health Organization. (2010). Global Recommendations on Physical Activity for Health. http://www.who.int/dietphysicalactivity/factsheet_recommendations/en/ Accessed 25 January 2017.

World Health Organization (2018). WHOQOL: Measuring Quality of Life. http://www.who.int/healthinfo/survey/whoqol-qualityoflife/en/. Assessed 6 June 2018.

World Health Organisation (14 April, 2016). Dementia, fact sheets. http://www.who.int/mediacentre/factsheets/fs362/en/ Accessed: 25 January 2017.

World Medical Association. (2016). WMA Declaration of Helsinki-Ethical Principles for Medical Research Involving Human Subjects.

Youell, J., Callaghan, JE., \& Buchanan, K. (2016). 'I don't know if you want to know this': carers' understandings of intimacy in long-term relationships when one partner has dementia. Ageing and Society, 36, 946-967, doi: 10.1017/S0144686X15000045.

Zarhin, D. (2018). Conducting Joint Interviews With Couples: Ethical and Methodological Challenges. Qualitative Health Research, doi: 10.1177/1049732317749196. 